\title{
SYMPOSIUM
}

\section{Behaviorally spontaneous confabulation in limbic encephalitis: The roles of reality filtering and strategic monitoring}

\author{
LOUIS NAHUM, ${ }^{1}$ RADEK PTAK, ${ }^{1}$ BÉATRICE LEEMANN,${ }^{1}$ PATRICE LALIVE, ${ }^{2}$ AND \\ ARMIN SCHNIDER ${ }^{1}$ \\ ${ }^{1}$ Division of Neurorehabilitation, Department of Clinical Neurosciences, University Hospitals and University of Geneva, Switzerland \\ ${ }^{2}$ Division of Neurology, Department of Clinical Neurosciences, University Hospitals and University of Geneva, Switzerland \\ (Received January 17, 2010; Final Revision June 13, 2010; AcCePTed July 14, 2010)
}

\begin{abstract}
Behaviorally spontaneous confabulation is characterized by a confusion of reality evident in currently inappropriate acts that patients justify with confabulations and in disorientation. Here, we describe a 38-year-old woman lawyer hospitalized because of non-herpetic, presumably autoimmune, limbic encephalitis. For months, she considered herself at work and desperately tried to respect her falsely believed professional obligations. In contrast to a completely erroneous concept of reality, she did not confabulate about her remote personal past. In tasks proposed to test strategic retrieval monitoring, she produced no confabulations. As expected, she failed in tasks of reality filtering, previously shown to have high sensitivity and specificity for behaviorally spontaneous confabulation and disorientation: she failed to suppress the interference of currently irrelevant memories and she had deficient extinction capacity. The observation underscores the special status of behaviorally spontaneous confabulation among confabulatory phenomena and of reality filtering as a thought control mechanism. We suggest that different processes may underlie the generation of false memories and their verbal expression. We also emphasize the need to present theories of confabulation together with experimental tasks that allow one to empirically verify the theories and to explore underlying physiological mechanisms. (JINS, 2010, 16, 995-1005.)
\end{abstract}

Keywords: Orbitofrontal cortex, Limbic system, Reality monitoring, Rehabilitation, Paramnesia, Caudate

\section{INTRODUCTION}

Confabulation describes the emergence of memories of events and experiences that never happened (Wernicke, 1900). Diverse classifications have been proposed, usually in the form of dichotomies reflecting variations that the authors perceived in their specific patient population. From this literature, at least four different forms emerge (Schnider, 2008):

(1) Provoked confabulations in the form of intrusions in memory tests (Kopelman, 1987; Schnider, von Daniken, \& Gutbrod, 1996a). These also occur in healthy subjects (Burgess \& Shallice, 1996).

(2) Momentary confabulations which are false statements that patients make up in discussions or upon questioning

Correspondence and reprint requests to: Armin Schnider, Service de Neurorééducation, Hôpitaux Universitaires de Genève, Av. de Beau-Séjour 26, CH-1211 Geneva 14 / Switzerland. E-mail: armin.schnider@hcuge.ch
(Berlyne, 1972; Bonhoeffer, 1901). They are the most frequently reported form of confabulation. They do not have a strict anatomical basis (Gilboa \& Moscovitch, 2002; Schnider, 2008), may occur or disappear during the course of a disease, and likely have diverse mechanisms.

(3) Fantastic confabulations which are implausible and defy logical thinking. This form is rare and has been described in severe dementia, delirium (Damasio, Graff Radford, Eslinger, Damasio, \& Kassel, 1985), and psychosis (Kraepelin, 1886, 1887; presumably also Gundogar \& Demirci, 2006).

(4) Behaviorally spontaneous confabulations in which thought and behavior are guided by memories that do not pertain to ongoing reality (Schnider et al., 1996a; Schnider \& Ptak, 1999). Patients act on the basis of memories, which may have correctly guided their behavior in the past, such as professional obligations, but 
which do not pertain to present reality, for example, their status of being hospitalized. This disorder is associated with severe amnesia and disorientation. While etiologies vary, lesions consistently involve the posterior medial orbitofrontal cortex (OFC) or structures directly connected with it (Schnider, 2003, 2008).

Proposed mechanisms of confabulations range from a desire to fill gaps in memory to disorders of high level monitoring mechanisms (see review in Schnider, 2008). Most theories were derived from clinical observation and were suggested to account for all types of confabulation. Another model was derived from observations in healthy subjects (Burgess \& Shallice, 1996) and then applied to a severe confabulator (Burgess \& McNeil, 1999). However, most theories have no empirical basis, that is, they lack an experimental procedure that would allow one to test their validity in confabulating patients and to explore the physiological underpinnings of the proposed mechanisms. Exceptions to this rule are Moscovitch's "strategic retrieval hypothesis," which applies to diverse forms of confabulation (Gilboa, Alain, Stuss, Melo, Miller, \& Moscovitch, 2006; Moscovitch, 1989, 1995), and Schnider's "reality filter hypothesis", which specifically applies to behaviorally spontaneous confabulation (Schnider, 2003, 2008). These two theories have been verified with specific experimental paradigms in groups of confabulating patients.

"The strategic retrieval model" elaborated by Moscovitch and co-workers (Gilboa et al., 2006; Moscovitch, 1989, 1995; Moscovitch \& Melo, 1997) conceives of confabulations as an impairment of memory retrieval processes. The model distinguishes between two forms of retrieval: associative retrieval which allows a cue to automatically activate a memory, and strategic retrieval which is self-initiated and effortful. At least one subcomponent organizes the memory search; another subcomponent monitors the output of the memory search and verifies the recovered memory trace. According to this hypothesis, confabulations arise when the subcomponent of monitoring is deficient. Specifically, confabulations would be the consequence of the conjunction of the activation of a faulty memory followed by deficient monitoring of the recovered memory. To test their hypothesis, Moscovitch and co-workers presented specific cue words to patients and asked them to provide a personal experience (episodic retrieval) or a historical event (semantic retrieval) related to each cue (Moscovitch \& Melo, 1997). Another technique was to have patients recount details of fairy tales or bible parts (Gilboa et al., 2006). The authors found that patients classified as confabulating amnesics produced more confabulations than non-confabulating amnesics and controls in fairy tales and bibles stories and in both versions of the cue words task (Gilboa et al., 2006; Moscovitch \& Melo, 1997). Whereas at initial presentation, the theory appeared to apply particularly to momentary confabulations (presence of confabulations in the cue task was also a criterion for classifying patients as confabulators; Moscovitch \& Melo, 1997), the theory was later extended to behaviorally spontaneous confabulation (Gilboa et al., 2006).
Schnider's "reality filter hypothesis" specifically refers to behaviorally spontaneous confabulation and disorientation. It tries to explain the reality confusion characterizing these disorders (Schnider, 2003, 2008). It is based on the observation that this form of confabulation is strongly associated with an inability to distinguish between memories relating to current reality and memories that do not. Specifically, when performing repeated runs of a continuous recognition task composed of the same pictures, the patients failed to realize whether they had seen an item in the ongoing run ("current reality") or in a previous run ("past reality"); they had an abnormal increase of false positive responses from the second run on (Schnider et al., 1996a; Schnider \& Ptak, 1999). This failure also very strongly predicted disorientation (Schnider, von Daniken, \& Gutbrod, 1996b) and paralleled the individual clinical course of the patients (Schnider, Ptak, von Daniken, \& Remonda, 2000). Positron emission tomography studies with healthy subjects performing adapted versions of the same task demonstrated activation of the posterior orbitofrontal cortex (area 13) (Schnider, Treyer, \& Buck, 2000) and subcortical loops (Treyer, Buck, \& Schnider, 2003). An evoked potential study indicated that the correct judgment of items as not-pertaining-to-now (the avoidance of false positive responses) occurs at an early stage of processing, at approximately 200-300 ms, before processes of (conscious) recognition and re-encoding set in (Schnider, Valenza, Morand, \& Michel, 2002). Based on these findings, the reality filter hypothesis holds that the reality confusion characterizing behaviorally spontaneous confabulation emanates from the failure of a preconscious orbitofrontal mechanisms that suppresses the interference of memories that do not pertain to ongoing reality (Schnider, 2008). This result also differentiates our task from exclusion paradigms which require conscious processing to retrieve contextual information (Jacoby, 1991; Mandler, 1980).

As to the mechanism underlying reality confusion, a recent study showed that behaviorally spontaneous confabulation and disorientation are strongly associated with a failure to abandon previously valid anticipations once they are no longer valid; the patients had deficient extinction capacity (Nahum, Ptak, Leemann, \& Schnider, 2009).

Thus, the reality filter theory specifically tries to explain the false sense of reality that is manifest in behaviorally spontaneous confabulation and disorientation; it proposes that the brain uses an ancient biological faculty - extinction - to keep thought in phase with reality, and that a failure of extinction induces the inability to sense that an upcoming memory (thought) does not relate to ongoing reality (Schnider, 2008; Nahum et al., 2009). However, the theory is not meant to explain the propensity of patients to talk about their falsely conceived reality, that is, the intensity of the "momentary" confabulations.

In this study, we describe a patient with non-herpetic limbic encephalitis who presented typical, severe and persistent behaviorally spontaneous confabulation and disorientation. However, she did not confabulate in task commonly used to probe the presence of momentary (purely verbal) confabulations. The 
case allowed us to explore the respective role of strategic monitoring and reality filtering in the generation of behaviorally spontaneous confabulation.

\section{CASE REPORT}

A 38-year-old, previously healthy woman was admitted to Neurology for insidiously developing amnesia. She had started to have difficulty in recognizing familiar people and organizing her work as a lawyer 1 month previously. More and more, she forgot appointments, lost files, and became confused. At admission, there was severe amnesia and disorientation; the patient was very concerned about her bad memory.

Magnetic resonance imaging (MRI) (Figure 1) showed an area of abnormal signal in the bilateral medial temporal lobes including amygdala and hippocampus, more marked on the left side, with extension into the insula, the posterior medial orbitofrontal and ventromedial prefrontal cortex, and the caudate nucleus on both sides. Initial cerebrospinal fluid (CSF) examination showed a mild lymphomonocytic pleocytosis (20 leukocytes/ $\mu \mathrm{L})$, normal protein
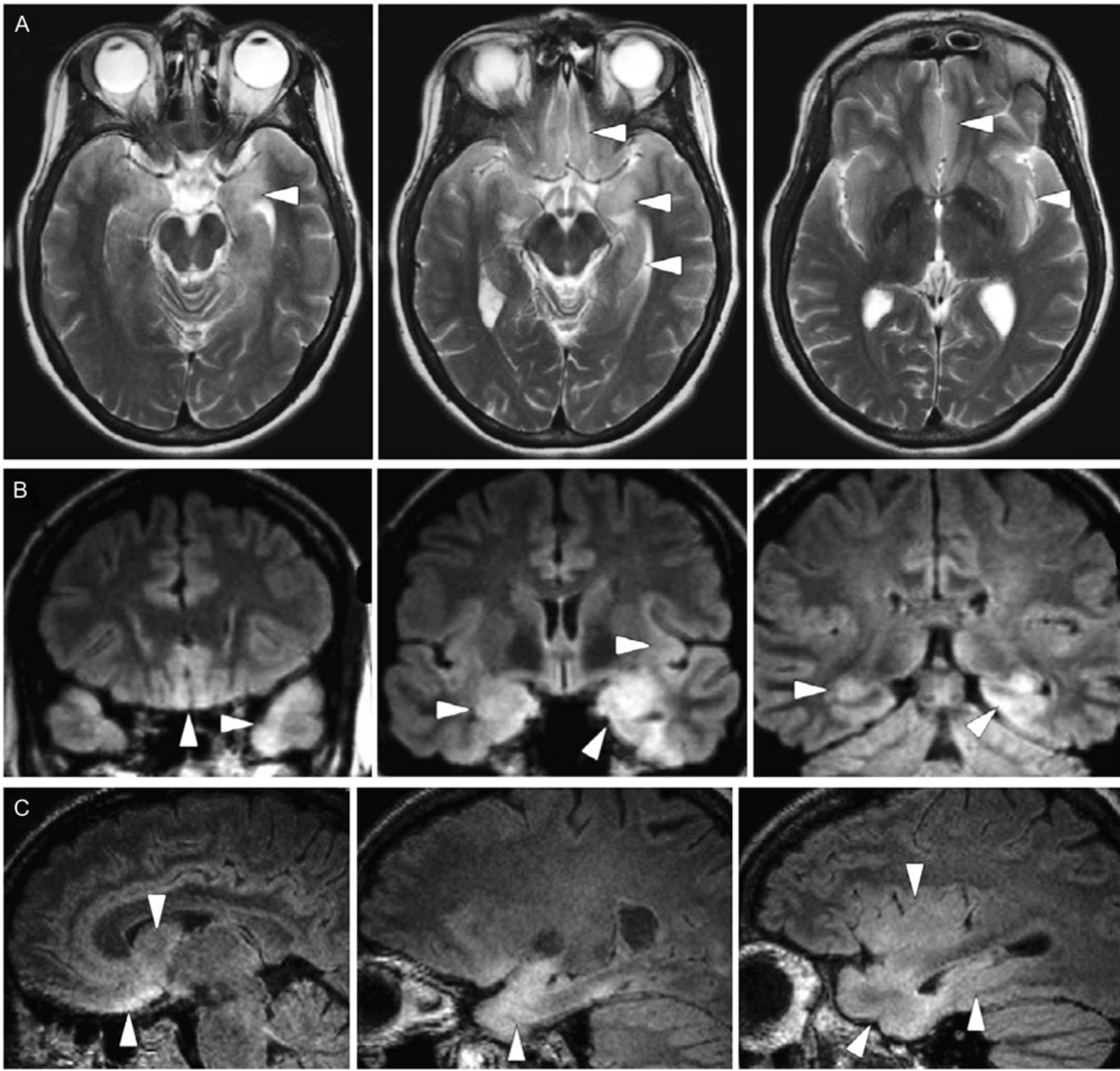

Fig. 1. Extension of the inflammation 6 weeks after start of the encephalitis. Arrowheads indicate regions of abnormal signal. (A) T2weighted axial magnetic resonance images (TR 104, TE $4000 \mathrm{~ms}$ ) showing diffuse inflammation of the medial orbitofrontal cortex (OFC), the anterior medial temporal lobe (MTL), hippocampus, and insula. (B) Coronal and (C) sagittal Flair images (TR $441 \mathrm{~ms}$, TE $6000 \mathrm{ms)}$ indicating extended inflammation of the medial orbitofrontal (gyrus rectus) and ventromedial prefrontal cortex extending into the caudate nucleus; the MTL, including amygdala and hippocampus, perirhinal and parahippocampal cortex, and extension in to the insula. 
and glucose levels, and positive intrathecal IgG synthesis with oligoclonal bands. Toxic, metabolic and infectious work-up, including cerebrospinal fluid (CSF) polymerase chain reaction (PCR) for Herpes 1 to 6, were negative. Extensive oncological workup, including abdominal computed tomography (CT), pelvic ultrasound, mammography and whole body positron emission tomography (PET) -CT, were negative. Paraneoplastic and autoimmune auto-antibodies, including all hitherto known antibodies associated with limbic encephalitis (anti-neuronal, -GAD, -Hu, -Ri, -YO, CV2/CRMP, -Amphiphysin, -Ma2, -NMDA, -VGKC, -neuropil; laboratories of Prof. A. Vincent, Oxford, and Prof. J. Dalmau, Philadelphia), were negative. A brain biopsy revealed microglial and lymphocytic infiltration. A treatment with acyclovir for 3 weeks was initiated with no effect. Highdose intravenous methlyprednisolone and subsequent intravenous immunoglobulins appeared to slow, but not to halt progression. Despite the absence of a tumor or a specific autoantibody, the clinical findings, the CSF, the brain biopsy, and the MRI were compatible with limbic encephalitis (identification of an anti-neuronal antibody may help but is not required for the diagnosis; Andersen and Barber, 2008).

The patient was transferred to neurorehabilitation 2 months after the initial manifestations. The clinical condition, as described below, remained stable for approximately 2 months (2-4 months after the beginning), but then slowly worsened with increasing anomia, anxiety, and depression. Cerebrospinal fluid showed normal cell count and protein but persistence of oligoclonal bands. MRI showed less inflammation, but generalized brain atrophy slowly set in over the next months. All testing described in the following was conducted in the first 2 months in neurorehabilitation, in which the patient's condition was stable.

\section{Behavioral Observation}

Upon admission, the patient was anxious, paced around in the unit in search of other people, explored other bedrooms in an indefinable search of something, then indicated that she searched for someone from her family or from the office. In the night she was agitated and often left the bedroom in the conviction that she had to go to the office to prepare some work. She also confused people and kissed other patients in the belief that she knew them. She correctly recognized her parents and her husband, although she denied being married. She did not remember having a 1-year-old child but caressed him on visits, although she denied recognizing him.

It was difficult to motivate her for therapies as she was convinced that she had to go to work. For approximately 2 months, professional obligations were the dominant confabulatory theme. She appeared to believe that the unit was part of her lawyer's study and permanently searched for her colleagues and for legal files. She repeatedly tried to leave the hospital so that the unit's automatic door-locking system had to be activated (magnetic wristlet locking the door and elevators as she approached them).

The following interview gives an impression of her false ideas about where she was and what her role was. It took place in her hospital bedroom 4 weeks after admission to neurorehabilitation.

The examiner (A.S.), who had followed the patient since admission, wore a white coat and was easily recognizable as a physician:

Examiner: "Do you recognize me?"

Patient: "I think we have never met. ... Well we have already met, but we have never worked together".

E: "Do you know why we are here, in this room?"

P: "Me? Yes, because I have a client. But we will talk about this in the presence of the judge. We have to review the status of both of them: what they want, whether they want to stay together. This is a proceeding of divorce, but they want to stay together."

E: "What have you been doing this morning?"

P: "I have seen the son. That is, one of them, because there are two."

E: "What will you do this afternoon?"

P: "Well, I have finished now. I have just seen the son. One of them, because there are several."

E: "So, what do have on the program for this afternoon?"

P: "I will be there."

E: "To do what?"

P: "Respond to the questions."

E: "What place is this? How is it called?"

P: "We are in court."

E: "Do you know my profession?"

P: "You are a jurist ... a lawyer ... a judge."

E: "I wear a white coat."

P: "A judge."

E: "You think I am a judge?"

The examiner shows his badge which indicates that he is professor and chief physician. The patient looks at the badge and continues:

P: "I don't know. It says 'chief physician'."

E: "And what does this mean?"

P: "That you're not a judge ... Professor? So, it is rather the scientific side, ... that you assure the quality-my quality—as a colleague".

Shortly after the interview, the patient was again in the hallway searching for her partners. This confabulatory theme dominated throughout her stay in neurorehabilitation and was only exchanged by two other ideas held for approximately 2 weeks: One day, in springtime, she was particularly anxious because she was convinced that her brother was waiting for her to go skiing. For days, she walked up and down the unit, obviously distressed by the fact that she could not find her brother who was waiting for her. After approximately 2 weeks, a new idea came up: she desperately searched for her badminton partner who was waiting for her somewhere in the unit. One week later, this idea was again replaced by her conviction that she had professional obligations as a lawyer in our unit or at court. 


\section{Neuropsychological Evaluation}

Neuropsychological evaluation was performed regularly from one month to three months after her admission (2 to 4 months after the beginning of the disease) when confabulatory behavior, disorientation and memory failure were stable. Results were stable over time. The study was approved by the Ethical Committee of the University Hospital of Geneva.

The patient was collaborative and alert during testing. Language was fluent but marked by word-finding difficulties. Table 1 summarizes the results of formal neuropsychological testing. There was marked anomia and slight deficit of semantic memory as evaluated by the Pyramid and Palm Tree Test (Howard \& Patterson, 1992). Comprehension, reading and writing were intact. Attentional, arithmetic, visuo-constructive, and visuospatial capacities were intact, as well as perception, except for deficient recognition of famous faces (although immediate recognition of anonymous faces was normal). Evaluation of executive functions showed normal interference control and figural fluency, whereas verbal fluency and planning ability were deficient. Despite marked anomia and memory impairment, intelligence was still in the normal range.

There was severe verbal and non-verbal anterograde amnesia with impaired learning, absent delayed free recall, and uncontrolled recognition with a high false positive rate. Retrograde amnesia, as determined with the Autobiographical interview (Kopelman, 1989), was also severe and concerned all life periods, with preservation of semantic memory for early childhood. Responses were non-specific, but not confabulatory; the common response was "I don't know."

Orientation to time, place, and current situation was severely deficient. She produced confabulations in response to questions concerning her current situation (e.g., to the question of why she was in the hospital, she answered that she was working on a legal case) and in response to questions probing autobiographical episodic memory (e.g., to the question about what she had done the day before, she answered that she had gone to a school to meet a person for a legal case) and future activities (e.g., to the question about what she intended to do in the afternoon, she answered that she planned to go back to her office to finish a report). Confabulations in response to questions regarding semantic personal information were restricted to her age (she sometimes reported that she was 10 years younger) and on one occasion to her profession (she said that she was a medical student).

\section{Strategic Monitoring}

Diverse tasks probing strategic monitoring have been proposed (Gilboa et al., 2006), including the analysis of errors in detailed recounts of bible stories or fairy tales. In this study, we used the following tests:

\section{Confabulation Questionnaire}

According to the strategic retrieval hypothesis, confabulations should occur both in episodic and semantic memory, as both require strategic retrieval (Moscovitch \& Melo, 1997). Dalla
Table 1. Neuropsychological results

\begin{tabular}{|c|c|c|}
\hline Neuropsychological test & Patient & Percentile \\
\hline $\begin{array}{l}\text { Orientation score (von Cramon } \\
\text { and Säring, 1982) }\end{array}$ & 6 & $\begin{array}{c}\text { Normal } \\
\text { score } \geq 16\end{array}$ \\
\hline \multicolumn{3}{|l|}{ WAIS-R (Tewes, 1991) } \\
\hline Verbal IQ & 94 & 34 \\
\hline Performance IQ & 91 & 27 \\
\hline Total IQ & 92 & 30 \\
\hline \multicolumn{3}{|l|}{ WMS-R (Wechsler, 1987) } \\
\hline Attention & 96 & 39 \\
\hline Verbal & $<50$ & $<1$ \\
\hline Visual & $<50$ & $<1$ \\
\hline General & $<50$ & $<1$ \\
\hline Delay & $<50$ & $<1$ \\
\hline \multicolumn{3}{|c|}{$\begin{array}{l}\text { Autobiographical memory interview } \\
\text { (Kopelman, Wilson, \& Baddeley, 1989) }\end{array}$} \\
\hline Childhood semantic & 12 & \\
\hline Childhood autobiographic & 1 & \\
\hline Adult semantic & 1 & \\
\hline Adult autobiographic & 0 & \\
\hline Recent semantic & 0 & \\
\hline Recent autobiographic & 0 & \\
\hline Digit span (Wechsler, 1945) & 6 & 27 \\
\hline Corsi block tapping (Milner, 1971) & 5 & 16 \\
\hline \multicolumn{3}{|l|}{$\begin{array}{c}\text { California Verbal Learning Test (Delis, } \\
\text { Kramer, Kaplan, \& Ober, 1987) }\end{array}$} \\
\hline Trial 5 & 4 & $<1$ \\
\hline Sum trials $1-5$ & 10 & $<1$ \\
\hline Long delay free recall & 0 & $<1$ \\
\hline Recognition, correct & 10 & $<1$ \\
\hline Recognition, false positives & 19 & $<1$ \\
\hline $\begin{array}{l}\text { Pyramids and Palm Trees Test } \\
\text { (Howard and Patterson, 1992) }\end{array}$ & 43 & \\
\hline $\begin{array}{l}\text { Boston Naming Test (Kaplan, } \\
\text { Goodglass, \& Weintraub, } 1983\end{array}$ & 12 & $<1$ \\
\hline \multicolumn{3}{|c|}{ Word fluency (Thurstone and Thurstone, 1963) } \\
\hline Total number of words & 8 & 2 \\
\hline \multicolumn{3}{|l|}{$\begin{array}{l}\text { Design fluency (Regard, Strauss, \& } \\
\text { Knapp, 1982) }\end{array}$} \\
\hline Total number of designs & 31 & 21 \\
\hline \multicolumn{3}{|l|}{$\begin{array}{l}\text { Stroop test, interference condition } \\
\text { (Heaton et al., 1993) }\end{array}$} \\
\hline Seconds & 22 & 74 \\
\hline Errors & 1 & 40 \\
\hline
\end{tabular}

Barba's (1993) Confabulation Questionnaire contains subtests with questions concerning personal and general semantic memory, episodic memory, orientation for space and time, and semantic and episodic memory questions to which the appropriate response is "I don't know." Table 2 summarizes the patient's performance. She did not confabulate on any "I don't know" or general semantic question. Performance was poor on all subtests except semantic and episodic questions to which the correct response was "I don't know" (Table 2). Only four confabulations were evoked: three in response to questions about episodic memory ("What did you do yesterday? Who did you meet yesterday? When did you go to the restaurant for the last time?") and one in response to a personal semantic question 
Table 2. Patient's and normal controls' performance on the Confabulation Battery and the Crovitz Test

\begin{tabular}{|c|c|c|c|c|}
\hline Task & $\begin{array}{l}\text { Patient } \\
\text { Scores }\end{array}$ & $\begin{array}{l}\text { Confabulations } \\
\text { (number) }\end{array}$ & $\begin{array}{l}\text { Controls } \\
\text { Scores }\end{array}$ & $\begin{array}{l}\text { Confabulations } \\
\text { (number) }\end{array}$ \\
\hline \multicolumn{5}{|l|}{ Confabulation Battery } \\
\hline Personal semantic memory & $12 / 20$ & 0 & $20 \pm 0$ & 0 \\
\hline Episodic memory & $6 / 15$ & 3 & $13.95 \pm 0.9$ & 0 \\
\hline Orientation time-place & $1 / 10$ & 5 & $10 \pm 0$ & 0 \\
\hline General semantic memory & $4 / 15$ & 0 & $13.95 \pm 1$ & 0 \\
\hline Linguistic semantic memory & $5 / 15$ & 0 & $13.5 \pm 1.2$ & 0 \\
\hline I don't know episodic & $10 / 10$ & 0 & $10 \pm 0$ & 0 \\
\hline I don't know semantic & $10 / 10$ & 0 & $10 \pm 0$ & 0 \\
\hline \multicolumn{5}{|l|}{ Crovitz Test } \\
\hline Episodic & $14 / 24$ & 0 & $22.8 \pm 4$ & 0 \\
\hline Semantic & $16 / 24$ & 0 & $21.6 \pm 4$ & 0 \\
\hline
\end{tabular}

Note. Normal control data (from 12 healthy adults subjects) taken from Dalla Barba et al. (1997).

relating to situational orientation ("Why are you in the hospital?"). Thus, the patient confabulated in response to questions regarding her personal status (she was disoriented) but not in response to semantic questions; thus, she did not have a general "monitoring" failure that would be expected if she had deficient strategic retrieval.

\section{Crovitz Cue Word Test}

The absence of confabulations in the semantic subtests of the Confabulation Battery might theoretically be due to low strategic demands. We, therefore, applied Moscovitch's version of the Crovitz cue-word test (Crovitz \& Schiffman, 1974; Moscovitch, 1995), which poses high and equal demands on strategic retrieval from episodic and semantic memory (Moscovitch \& Melo, 1997). The patient was asked to describe details of a specific event from her personal life (episodic memory) or historical events (semantic memory) related to 12 cues words. Cue words for personal events were: "angry, break, dog, find, game, happy, letter, lonely, make, river, successful, throw"; cue words for historical events were: "assassination, battle, exploration/explorer, fire/natural disaster, Indians/settlers, invention/scientific discovery, miracle, queen/king, revolt/ rebellion, saint, sea/ocean, train." Responses were scored on a $0-3$ scale with 3 points for a full detailed description including time and location; 2 points for a specific event with some details but lacking information about place and time; 1 point for non-specific information about an event; 0 point if nothing was provided. Two independent raters scored the responses and checked for the presence of confabulations. Table 2 shows that the patient badly performed in both the semantic and the episodic part of the test, but gave a response to each cue word; most recalled events were non-specific, except six recalled in detail. Most reported events related to childhood. Most importantly, she produced absolutely no confabulation in response to any cue-word, indicating that strategic retrieval processes were not impaired.

\section{Supplementary Material}

To view the verbatim description of two personal events and four historical events, please access an online-only supplementary appendix. Please visit journals.cambridge. org/INS, then click on the link "Supplementary Material" at this article.

\section{Reality Filter}

\section{Memory selection}

We tested the capacity to select memories pertaining to the present with an experimental task used in several previous studies (Ptak \& Schnider, 1999; Schnider et al., 1996a, 1996b; Schnider, Bonvallat, et al., 2005; Schnider, Ptak, et al., 2000; Schnider, 2008). This task has two runs of a continuous recognition test, composed of the same meaningful pictures (Snodgrass \& Vanderwart, 1980); the only difference between the runs is that pictures are presented in different order. Subjects are asked to indicate picture recurrences only within the ongoing run. Thus, in the second run, they have to disregard familiarity with items from the previous run. The first run assesses pure information storage, which is calculated as: Hits - false positives. The interesting part is the second run, which is made 45-60 min later. As all pictures have already been presented in the first run, subjects sense at least some familiarity with them; thus, the second run requires the ability to distinguish between items' previous occurrence in the currently ongoing rather than the previous first run (Schnider et al., 1996a,b).

Healthy subjects generally performed very well on this task. Indeed, in imaging studies, the task had to be much more difficult (target items repeated only once to twice rather than five times; runs separated by one minute rather than 45 $60 \mathrm{~min}$ ) to be resented as a challenge by the subjects - as they indicated when questioned - and to induce consistent brain activation; performance still was virtually perfect (Schnider, Treyer, et al., 2000; Schnider et al., 2002; Treyer et al., 2003). 
[We succeeded in significantly lowering performance only when we used non-verbalizable geometric forms presented in rapid succession with short sequences ("runs") separated only by one intervening stimulus (Schnider, Guggisberg, Nahum, Gabriel, \& Morand, 2010).]

Although our task can be formally considered a recollection task (Mandler, 1980), the anatomical specificity (Schnider, Treyer, \& Buck, 2000; Treyer et al., 2003) and the ease with which healthy subjects perform it also distinguishes it from other, effortful tasks such as the processdissociation procedure (Jacoby, 1991) or other source monitoring and temporal order tasks (Hirst \& Volpe, 1982; Janowsky, Shimamura, \& Squire, 1989; Johnson, O'Connor, \& Cantor, 1997; Kopelman, Stanhope, \& Kingsley, 1997; Schnider, Gutbrod, Hess, \& Schroth, 1996), which may be impaired in amnesic patients or patients with prefrontal lesions without amnesia. None of these tasks has shown to be specific for any type of confabulation.

Using our task in the version described above, we found that, in contrast to healthy subjects and non-confabulating amnesics, behaviorally spontaneous confabulators had a marked performance drop in the second run due to a steep increase of false positives (Schnider et al., 1996a). We described this performance drop as "temporal context confusion" (TCC = FP2/Hits2 - FP1/Hits1), where Hits1,2 is the number of correctly recognized picture repetitions (maximum, 40), FP1,2 is the number of false positive responses in runs 1,2 (max. 80). In our studies, healthy subjects and nonconfabulating patients had TCC $<0.3$, while behaviorally spontaneous confabulators had TCC $\geq 0.3$ (Schnider et al., 1996a; Schnider, Ptak, et al., 2000; Schnider, 2008). TCC also very strongly correlated with orientation as measured with 20 questions (Schnider et al., 1996b).

The present patient had a severe storage deficit already in the first run with only 28 hits (of 40) and 16 false positives (of 80). Most importantly, performance sharply dropped in the second run (13 hits; 19 false positives), yielding a TCC of 0.89 , indicating that she failed to distinguish between memories that pertain to "now" and memories that do not. Her performance was somewhat atypical in that most (but not all) previous behaviorally spontaneous confabulators primarily increased their false positives in the second run, rather than showing such a marked decrease of hits (Schnider \& Ptak, 1999; Schnider, Ptak, et al., 2000). However, occasional patients expressed their uncertainty in the second run by such striking reluctance to admit familiarity ("no" response to any item) that TCC became difficult to measure (Ptak \& Schnider, 1999). We have interpreted this behavior as a indication of intact self monitoring.

\section{Extinction capacity}

According to imaging and electrophysiological studies using adapted versions of the paradigm described in the previous paragraph in healthy subjects, the ability to distinguish between memories that pertain to ongoing reality and memories that do not depends in particular on activity in OFC area
13 (Schnider, Treyer, et al., 2000) and subcortical structures involving known components of the so-called reward system (Treyer et al., 2003). This distinction (filtering) process has an electrocortical correlate -absence of a specific electrocortical map configuration-at an early stage in the re-activation of memories, at 200-300 ms, that is, even before the content of an upcoming memory is consciously recognized and again encoded (Schnider, 2003; Schnider et al., 2002).

The mechanism behind this selection or filtering process has been unclear. We suspected that it depended on extinction capacity, the ability to learn that a previously valid anticipation no longer applies. The present case exemplifies the basis for this hypothesis: the patient completely failed to integrate the permanent absence of the events that she had anticipated into her thinking (see the interview in the case description): Despite living in a hospital environment, she constantly anticipated to find colleagues and judges relating to her professional habits. This failure to abandon previously valid anticipations when they no longer apply corresponds to a deficit of extinction. In primates, a specific extinction failure was documented after lesions of the posterior medial orbitofrontal cortex, more specifically, area 13 (Butter, 1969). Single cell recordings revealed neurons in this area that specifically fired when an anticipated reward was not delivered (Rosenkilde, Bauer, \& Fuster, 1981), thus signaling the absence of an anticipated outcome. We found that in humans, this area also activates when subjects anticipate and process outcomes that have no tangible reward value (Schnider, Treyer, et al., 2005). Electrophysiologically, the non-emergence of anticipated outcomes (extinction trials) induced a specific electrocortical response at an early stage of outcome processing, 200-300 ms (Schnider, Mohr, Morand, \& Michel, 2007).

Based on these considerations, we recently explored extinction capacity in patients presenting behaviorally spontaneous confabulation and disorientation. We found that both disorders are indeed strongly and specifically associated with a failure of extinction capacity (Nahum et al., 2009). The present patient participated in that study, in which we applied a simple experimental task of association learning and extinction. Participants repeatedly saw the same pair of faces on the screen and were asked to predict which one of the two faces would have a target stimulus (a spider) on its nose. Unbeknownst to the participants, the target stimulus was absent after four to six correct choices. The absence of the anticipated target (extinction trial) signaled that the target had switched to the other face. Two measures were calculated: (1) Association learning error rate, that is, the unmotivated abandonment of the face that had had the spider on the nose in the previous trial; (2) Post-extinction error rate, that is, the continued choice of the same face despite absence of the spider on its nose in the previous trial (extinction trial) (detailed description in Nahum et al., 2009).

Figure 2 highlights the patient's performance in comparison with other patients who had either amnesia, a lesion involving the orbitofrontal cortex, or both (OFC lesion with amnesia). Similar to the severely disorientated amnesics and the other four behaviorally spontaneous confabulators, she 

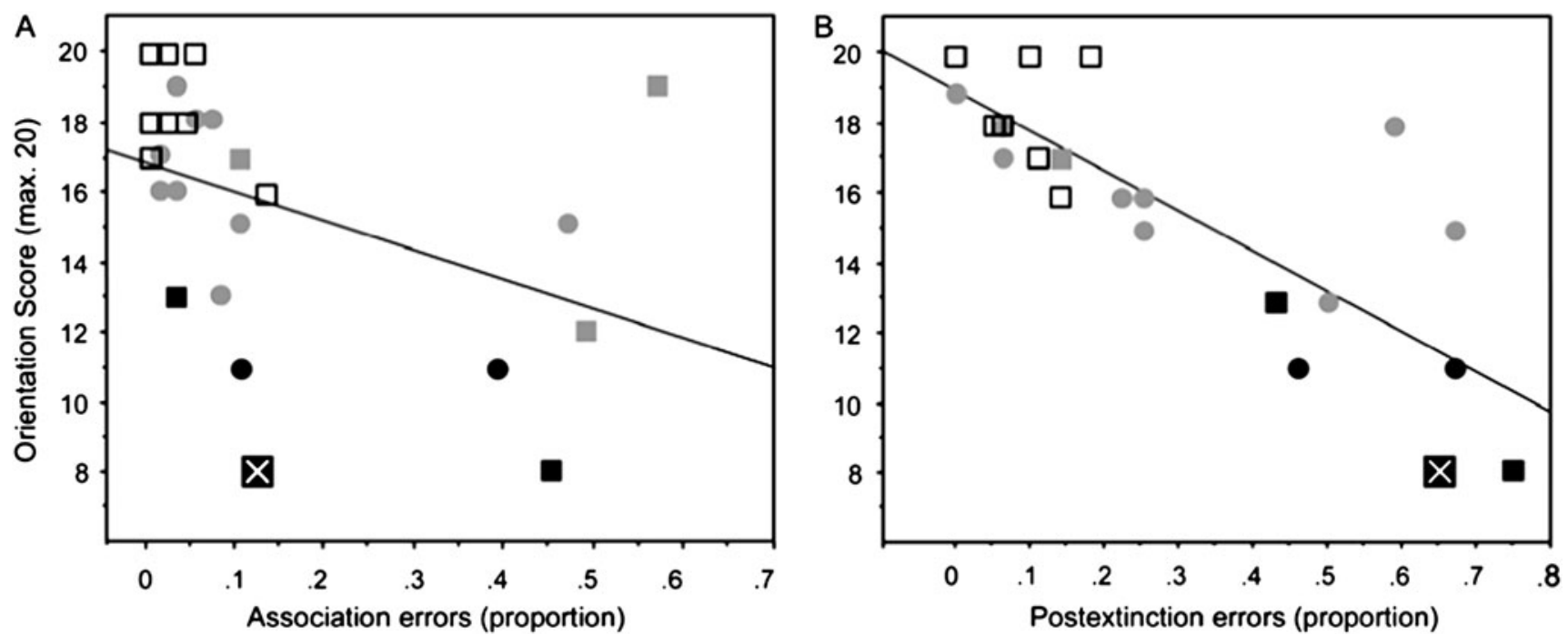

Fig. 2. Association learning and extinction capacity. The figure is similar to figure 2 in Nahum et al. (2009), except that the present patient's performance is highlighted by the black square with a white X. It shows the correlation of orientation with association learning error rate (A) and post-extinction error rate (B). Behaviorally spontaneous confabulators had significantly worse post-extinction rate than the other patients. Symbols have the following meaning: Black symbols, behaviorally spontaneous confabulators; gray symbols, non-confabulating amnesics; empty symbols, non-amnesic subjects; squares, subjects with radiologically proven damage of orbitofrontal cortex; round symbols, subjects with no radiologically proven orbitofrontal damage. The regression line refers to the analysis including all subjects. Figure adapted from Nahum et al. (2009) with permission from Elsevier Publishers.

easily learned the association ( $11.6 \%$ errors) but had a severe extinction failure: after $65 \%$ of the extinction trials, she continued to choose the previously correct face although the last (extinction) trial had shown that the target stimulus was no longer associated with it.

Of note, animal experiments showed that deficient extinction capacity is independent of other forms of disinhibition as tested, for example, in go/no-go paradigms (Rosenkilde, 1979). Clinical go/no-go testing in our patient as well as indirect measures (executive tasks listed in Table 1) revealed no particular perseverative behavior except for her permanent conviction that she had to do work as a lawyer.

\section{Clinical course}

For 4 months in rehabilitation, her state did not markedly evolve. She seemed to recognize her parents and her husband and took walks with them, which she rapidly forgot. However, she became more and more depressed and needed antidepressant medication. She was apparently aware of her memory difficulties, often cried, and spontaneously complained about the "confusion" in her memory: "Everything is mixed up in my head and I forget everything; I don't know what to do." Despite this insight, she was convinced that the personnel on the ward were colleagues of hers and that she had to leave the unit to go to court. At the same time, anomia worsened. After 4 months in rehabilitation, depression became more and more difficult to control, and the patient expressed suicidal ideas. She was transferred to a psychiatric inpatient ward. Mental abilities continued to worsen. After 1 year, she was profoundly demented and unable to collaborate in a controlled manner. While mood improved-she appeared amused and happy-language degenerated; she gesticulated and gibbered with imagined people, but failed to comprehensively respond to questions. She never recognized her child.

\section{DISCUSSION}

This patient presented all features of behaviorally spontaneous confabulation: she confabulated in response to questions, spontaneously acted according to these confabulations, was disoriented with regards to time, place, and her current role, and had severe amnesia. Similar to previously described behaviorally spontaneous confabulators (Schnider et al., 1996a; Schnider, 2008) and patients having disorientation (Schnider et al., 1996b), she failed to distinguish between memories that pertain to ongoing reality and memories that do not (Memory selection task). In agreement with her behavior, and similar to previously studied patients (Nahum et al., 2009), she had a specific failure of extinction capacity.

While failing in these tasks, which constitute the basis of the "reality filter hypothesis", she did not satisfy criteria of a failure of strategic retrieval monitoring in tasks proposed to test this hypothesis (Moscovitch, 1989; Moscovitch \& Melo, 1997): she did not confabulate in response to semantic questions and did not confabulate in tasks requiring retrieval of semantic or remote autobiographical memories. The absence of confabulations in such tasks is concordant with our earlier observation that behaviorally spontaneous confabulators, as defined above, had no increased tendency to respond to questions about seemingly famous people ("who is princess Lolita?"), or plausible but inexistent places ("where is Premola?") or objects (“what is a waterknube?”) (Schnider et al., 1996a). 
A deficit of strategic monitoring during memory retrieval was initially demonstrated in patients with momentary confabulations using methods that we also applied in the current study (Moscovitch \& Melo, 1997). More recently, the strategic retrieval account was also suggested to explain spontaneous confabulations, including the form observed in the present patient (Gilboa et al., 2006), although patient classification appeared to have been somewhat problematic (see discussion in Schnider, 2008, p. 252f.). In that study, patients were asked to retrieve bible stories and fairy tales, that is, semantic memories. When recalling the stories, the confabulating patients made more confabulations, which related both to time and content, thus satisfying a basic requirement of the theory.

Why, then, did our patient not produce confabulations in tasks of strategic monitoring? One interpretation would be that she had too deficient autobiographical and semantic memory to use it as a basis for confabulations; thus, strategic monitoring was not necessary. This interpretation neglects that she did produce responses to most questions. Importantly, however, this interpretation would also support the conclusion that our patient's reality confusion was indeed not due to defective strategic monitoring as measured by the tasks proposed to test it: if reality confusion can occur in the absence of autobiographical and semantic memories susceptible to be confabulated on, then the failure to monitor these non-existent memories can obviously not explain the reality confusion.

Another reason for the discrepancy between our results and that of Gilboa et al. (2006) might be different definitions of "spontaneous confabulations". The term was introduced by Pick (1905) to describe spontaneously produced confabulations, in contrast to confabulations provoked by suggestive questioning. Pick did not suggest different mechanisms. Kopelman (1987) revived this dichotomy and described provoked confabulations as those occurring in response to questions and in tests of memory; he considered them a normal response to a faulty memory. Spontaneous confabulations, in contrast, were considered a different, abnormal kind of confabulations characterized as sustained, wide-ranging, and fantastic. We made an even stronger distinction: we defined provoked confabulations as those appearing in memory tests and quantified them as the number of intrusions (Schnider et al., 1996a). By contrast, we used the term spontaneous confabulation in a strict sense, demanding that the confabulatory behavior was truly spontaneous. Our criterion for the spontaneity was that patients at least occasionally acted according to their false ideas (Schnider et al., 1996a; Schnider, Ptak, et al., 2000; Schnider \& Ptak, 1999). We now propose the term "behaviorally spontaneous confabulation" for this form of confabulation, which is probably always associated with disorientation and amnesia (Schnider, 2008) and indeed corresponds to the original version of Korsakoff's syndrome (Bonhoeffer, 1904). Thus, the discrepancy between our present findings and the interpretation of Gilboa et al. (2006) may result from a different definition of "spontaneous confabulations." Although the studies testing the strategic monitoring hypothesis included patients with undeniable reality confusion in the sense of behaviorally spontaneous confabulation (Gilboa et al., 2006; Moscovitch, 1989, 1995; Moscovitch \& Melo, 1997), we suspect that the theory will prove to be particularly helpful for understanding the verbal behavior of the patients-the momentary confabulations. The reality filter hypothesis, in contrast, is thought to explain the reality confusion in thinking and thus specifically applies to behaviorally spontaneous confabulations and disorientation, while it is not predictive regarding the intensity of the verbal expression of the reality confusion.

This interpretation also suggests that the production of confabulations, as they emerge in discussions, depends on the interplay between at least two processing stages:

(1) The generation of false memories. Candidate mechanisms for the emergence of false memories are deficits in the evocation and construction of memories (Moscovitch, 1989, 1995; Schacter, Norman, \& Koutstaal, 1998), deficient source monitoring (Johnson \& Raye, 1998), false temporality in thinking (Dalla Barba, Cappelletti, Signorini, \& Denes, 1997; Dalla Barba, 2002), deficient reality filtering (Schnider, 2008), and others.

(2) The verbal expression of false memories. Possible factors influencing patients' inclination to accept and communicate their false memories encompass deficient self-control (Benson et al., 1996) or strategic monitoring (Gilboa et al., 2006; Moscovitch, 1989, 1995; Moscovitch \& Melo, 1997), executive dysfunction (Metcalf, Langdon, \& Coltheart, 2007), a tendency to fill gaps in memory (Pick, 1905), motivational factors (Conway \& Tacci, 1996; Flament, 1957; Fotopoulou, Conway, Tyrer, Birchall, Griffiths, \& Solms, 2008), personality traits (Williams \& Rupp, 1938), and others.

In this schema, deficient reality filtering as explored in our studies (Schnider, 2008) explains only the reality confusion characteristic of behaviorally spontaneous confabulators and disorientation: a failure of the area-13-dependent, preconscious filter mechanism prevents the patients from sensing whether upcoming memories (thoughts) relate to ongoing reality or not. Whether they talk about their false ideas spontaneously or only in response to questions, may depend on other factors, for example personality traits (Williams \& Rupp, 1938) or motivational factors (Fotopoulou et al., 2008). This tendency possibly also depends on the type of brain damage and the lesion site; in patients with OFC destruction following rupture of an anterior communicating artery aneurysm, it may depend on deficient strategic monitoring (Gilboa et al., 2006).

In summary, the present case is consistent with previous studies indicating that behaviorally spontaneous confabulation is associated with a failure to distinguish between memories that pertain to ongoing reality and memories that do not. It also supports the idea that this failure results from deficient extinction capacity. At the same time, it shows that intense behaviorally spontaneous confabulation and disorientation need not be associated with failure in tasks proposed to test strategic monitoring. 
Of note, the conclusions from this study were only possible because both the strategic monitoring hypothesis and the reality filtering theory have specified experimental tasks associated with them. These tasks may be imperfect. Thus, the known strategic monitoring tasks cover only limited components of the theory. Conversely, the memory selection task testing the reality filter has shown its sensitivity and specificity for behaviorally spontaneous confabulation and disorientation only among patients with significant anterograde amnesia as determined with delayed free recall. In addition, performance is sensitive to strategies that some patients adopt in the face of the difficulty they sense in the second run of the task; occasional false positives (Gilboa et al., 2006) and false negatives (Ptak \& Schnider, 1999) have been reported. Finally, the extinction task used in this and our previous study (Nahum et al., 2009) requires explicit, conscious decisions. It is, therefore, unlikely to be a perfect measure of the pre-conscious process that reality filtering seems to be (Schnider et al., 2002). Nonetheless, the construction of tasks attempting to test theories of confabulation is crucial for future progress. Modern imaging and electrophysiological methods then offer the opportunity to compare mechanisms underlying different tasks reflective of reality filtering, source monitoring, strategic monitoring, or recollection depending on exclusion of other qualities than a memory's relation with ongoing reality. In any case, only theories verified with defined experimental procedures in properly controlled groups can be considered more than speculations and may offer the potential to explore physiological mechanisms underlying the generation of true and false memories.

\section{DISCLOSURE/CONFLICT OF INTEREST}

The authors declare no conflict of interest.

\section{ACKNOWLEDGMENTS}

We thank Asaf Gilboa for helpful comments. The study was supported by Swiss National Science Foundation grant no. 320000113436 to A.S.

\section{REFERENCES}

Anderson, N.E., \& Barber, P.A. (2008). Limbic encephalitis - A review. Journal of Clinical Neuroscience, 15, 961-971.

Benson, D.F., Djenderedjian, A., Miller, B.L., Pachana, N.A., Chang, L., Itti, L., et al. (1996). Neural basis of confabulation. Neurology, 46, 1239-1243.

Berlyne, N. (1972). Confabulation. British Journal of Psychiatry, 120, 31-39.

Bonhoeffer, K. (1901). Die Akuten Geisteskrankheiten des Gewohnheitstrinkers. Eine klinische Studie. Jena: Gustav Fischer.

Bonhoeffer, K. (1904). Der Korsakowsche Symptomenkomplex in seinen Beziehungen zu den verschiedenen Krankheitsformen. Allgemeine Zeitschrift für Psychiatrie und psychisch-gerichtliche Medicin, 61, 744-752.

Burgess, P.W., \& McNeil, J.E. (1999). Content-specific confabulation. Cortex, 35, 163-182.
Burgess, P.W., \& Schallice, T. (1996). Confabulation and the control of recollection. Memory, 4, 359-411.

Butter, C.M. (1969). Perseveration in extinction and in discrimination reversal tasks following selective frontal ablations in Macaca mulatta. Physiology and Behavior, 4, 163-171.

Conway, M.A., \& Tacci, P.C. (1996). Motivated confabulation. Neurocase, 2, 325-339.

Crovitz, H.F., \& Schiffman, H. (1974). Frequency of episodic memories as function of their ages. Bulletin of Psychonomic Society, 4, 517-518.

Dalla Barba, G. (1993). Confabulation: Knowledge and recollection experience. Cognitive Neuropsychology, 10, 1-20.

Dalla Barba, G.F. (2002). Memory, consciousness and temporality. Boston: Kluwer Academic Publishers.

Dalla Barba, G., Cappelletti, J.Y., Signorini, M., \& Denes, G. (1997). Confabulation: Remembering 'another' past, planning 'another' future. Neurocase, 3, 425-436.

Damasio, A.R., Graff Radford, N.R., Eslinger, P.J., Damasio, H., \& Kassel, N. (1985). Amnesia following basal forebrain lesions. Archives of Neurology, 42, 263-271.

Delis, D.C., Kramer, J.H., Kaplan, E., \& Ober, B.A. (1987). California verbal learning test: Adult version. San Antonio, TX: The Psychological Corporation.

Flament, J. (1957). La fabulation dans le syndrome de Korsakov d'étiologie traumatique. Considérations cliniques, psychopathologiques et neuro-pathologiques à propos d'une observation de fabulation à caractère mythopathique. Acta Neurologica Belgica, 57, 119-161.

Fotopoulou, A., Conway, M.A., Tyrer, S., Birchall, D., Griffiths, P., \& Solms, M. (2008). Is the content of confabulation positive? An experimental study. Cortex, 44, 764-772.

Gilboa, A., Alain, C., Stuss, D.T., Melo, B., Miller, S., \& Moscovitch, M. (2006). Mechanisms of spontaneous confabulations: A strategic retrieval account. Brain, 129, 1399-1414.

Gilboa, A., \& Moscovitch, M. (2002). The cognitive neuroscience of confabulation: A review and a model. In A.D. Baddeley, M.D. Kopelman, \& B.A. Wilson (Eds.), Handbook of memory disorders (2nd ed). London: John Wiley and Sons.

Gundogar, D., \& Demirci, S. (2006). Multiple sclerosis presenting with fantastic confabulation. General Hospital Psychiatry, 28, 448-451.

Hirst, W., \& Volpe, B.T. (1982). Temporal order judgments with amnesia. Brain and Cognition, 1, 294-306.

Howard, D., \& Patterson, K. (1992).Pyramids and palm trees: A test of semantic access from pictures and words. Bury St Edmunds: Thames Valley.

Jacoby, L.L. (1991). A process dissociation framework: Separating automatic from intentional uses of memory. Journal of Memory and Language, 30, 513-541.

Janowsky, J.S., Shimamura, A.P., \& Squire, L.R. (1989). Source memory impairment in patients with frontal lobe lesions. Neuropsychologia, 27, 1043-1056.

Johnson, M.K., O'Connor, M., \& Cantor, J. (1997). Confabulation, memory deficits, and frontal dysfunction. Brain and Cognition, 34, 189-206.

Johnson, M.K., \& Raye, C.L. (1998). False memories and confabulation. Trends in Cognitive Sciences, 2, 137-145.

Kaplan, E.F., Goodglass, H., \& Weintraub, S. (1983). The Boston naming test (2nd ed.). Philadelphia: Lea \& Febiger.

Kopelman, M.D. (1987). Two types of confabulation. Journal of Neurology, Neurosurgery, and Psychiatry, 50, 1482-1487. 
Kopelman, M.D., Stanhope, N., \& Kingsley, D. (1997). Temporal and spatial context memory in patients with focal frontal, temporal lobe, and diencephalic lesions. Neuropsychologia, 35, 1533-1545.

Kopelman, M.D., Wilson, B.A., \& Baddeley, A.D. (1989). The autobiographical memory interview: A new assessment of autobiographical and personal semantic memory in amnesic patients. Journal of Clinical and Experimental Neuropsychology, 11, 724-744.

Kraepelin, E. (1886). Ueber Erinnerungsfälschlungen (1/3). Archiv für Psychiatrie und Nervenkrankenheiten, 17, 830-843.

Kraepelin, E. (1887). Ueber Erinnerungsfälschlungen (2/3. Fortsetzung). Archiv für Psychiatrie und Nervenkrankenheiten, 18, 199-239.

Mandler, G. (1980). Recognizing: The judgment of previous occurrence. Psychological Review, 87, 252-271.

Metcalf, K., Langdon, R., \& Coltheart, M. (2007). Models of confabulation: A critical review and a new framework. Cognitive Neuropsychology, 24, 23-47.

Milner, B. (1971). Interhemispheric differences and psychological processes. British Medical Bulletin, 27, 273-277.

Moscovitch, M. (1989). Confabulation and the frontal system: Strategic versus associative retrieval in neuropsychological theories of memory. In H.L. Roedinger, \& F.I. Craik (Eds.), Varieties of memory and consciousness: Essay in honor of Endel Tulving. Hillsdale, NJ: Lawrence Erlbaum.

Moscovitch, M. (1995). Confabulation. In D.L. Schacter (Ed.), Memory distortion, Cambridge: Harvard University Press.

Moscovitch, M., \& Melo, B. (1997). Strategic retrieval and the frontal lobes: Evidence from confabulation and amnesia. Neuropsychologia, 35, 1017-1034.

Nahum, L., Ptak, R., Leemann, B., \& Schnider, A. (2009). Disorientation, confabulation, and extinction capacity: Clues on how the brain creates reality. Biological Psychiatry, 65, 966-972.

Pick, A. (1905). Zur Psychologie der Confabulation. Neurologisches Centralblatt, 24, 509-516.

Ptak, R., \& Schnider, A. (1999). Spontaneous confabulations after orbitofrontal damage: The role of temporal context confusion and self-monitoring. Neurocase, 5, 243-250.

Regard, M., Strauss, E., \& Knapp, P. (1982). Children's production on verbal and nonverbal fluency tasks. Perceptual and Motor Skills, 55, 839-844.

Rosenkilde, C.E. (1979). Functional heterogeneity of the prefrontal cortex in the monkey: A review. Behavioral and Neural Biology, 25, 301-345.

Rosenkilde, C.E., Bauer, R.H., \& Fuster, J.M. (1981). Single cell activity in ventral prefrontal cortex of behaving monkeys. Brain Research, 209, 375-394.

Schacter, D.L., Norman, K.A., \& Koutstaal, W. (1998). The cognitive neuroscience of constructive memory. Annual Review of Psychology, 49, 289-318.

Schnider, A. (2003). Spontaneous confabulation and the adaptation of thought to ongoing reality. Nature Reviews. Neuroscience, 4 , 662-671.

Schnider, A. (2008). The confabulating mind: How the brain creates reality. Oxford, New York: Oxford University Press.

Schnider, A., Bonvallat, J., Emond, H., \& Leemann, B. (2005). Reality confusion in spontaneous confabulation. Neurology, 65, 1117-1119.
Schnider, A., Guggisberg, A., Nahum, L., Gabriel, D., \& Morand, S. (2010). Dopaminergic modulation of rapid reality adaptation in thinking. Neuroscience, 167, 583-587.

Schnider, A., Gutbrod, K., Hess, C.W., \& Schroth, G. (1996). Memory without context. Amnesia with confabulations following right capsular genu. Journal of Neurology, Neurosurgery, and Psychiatry, 61, 186-193.

Schnider, A., Mohr, C., Morand, S., \& Michel, C.M. (2007). Early cortical response to behaviorally relevant absence of anticipated outcomes: A human event-related potential study. Neuroimage, $35,1348-1355$.

Schnider, A., \& Ptak, R. (1999). Spontaneous confabulators fail to suppress currently irrelevant memory traces. Nature Neuroscience, 2, 677-681.

Schnider, A., Ptak, R., von Daniken, C., \& Remonda, L. (2000). Recovery from spontaneous confabulations parallels recovery of temporal confusion in memory. Neurology, 55, 74-83.

Schnider, A., Treyer, V., \& Buck, A. (2000). Selection of currently relevant memories by the human posterior medial orbitofrontal cortex. Journal of Neuroscience, 20, 5880-5884.

Schnider, A., Treyer, V., \& Buck, A. (2005). The human orbitofrontal cortex monitors outcomes even when no reward is at stake. Neuropsychologia, 43, 316-323.

Schnider, A., Valenza, N., Morand, S., \& Michel, C.M. (2002). Early cortical distinction between memories that pertain to ongoing reality and memories that don't. Cerebral Cortex, 12, 54-61.

Schnider, A., von Daniken, C., \& Gutbrod, K. (1996a). The mechanisms of spontaneous and provoked confabulations. Brain, 119, 1365-1375.

Schnider, A., von Daniken, C., \& Gutbrod, K. (1996b). Disorientation in amnesia: A confusion of memory traces. Brain, 119, 1627-1632.

Snodgrass, J.G., \& Vanderwart, M. (1980). A standardized set of 260 pictures: Norms for name agreement, image agreement, familiarity, and visual complexity. Journal of Experimental Psychology: Human Learning \& Memory, 6, 174-215.

Tewes, U. (1991). HAWIE-R. Hamburg-Wechsler Intelligenztest für Erwachsene - Revision. Bern: Huber.

Thurstone, L.L., \& Thurstone, T.G. (1963). Chicago test of primary mental abilities. Chicago: Research Associates.

Treyer, V., Buck, A., \& Schnider, A. (2003). Subcortical loop activation during selection of currently relevant memories. Journal of Cognitive Neuroscience, 15, 610-618.

von Cramon, D.Y., \& Säring, W. (1982). Störung der Orientierung beim hirnorganischen Psychosyndrom. In D. Bente, H. Coper, \& S. Kanowski (Eds.), Hirnorganische Psychosyndrome im Alter (pp. 42-50). Berlin: Springer.

Wechsler, D. (1945). A standardized memory scale for clinical use. Journal of Psychology, 19, 87-95.

Wechsler, D. (1987). WMS-R. Wechsler memory scale - Revised. San Antonio, TX: The Psychological Corporation.

Wernicke, C. (1900). Grundriss der Psychiatrie in klinischen Vorlesungen. Leipzig: Thieme.

Williams, H.W., \& Rupp, C. (1938). Observations on confabulation. American Journal of Psychiatry, 95, 395-405. 